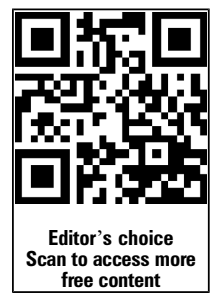

Department of Neurosurgery, Birmingham Children's Hospital, Birmingham, UK

\section{Correspondence to} Chirag Patel, Department of Neurosurgery, Birmingham Children's Hospital, Steelhouse Lane, Birmingham B4 6NH, UK viragpat@yahoo.com

Received 24 September 2013 Revised 31 July 2014 Accepted 1 August 2014 Published Online First 22 August 2014
CrossMark

To cite: Patel C, Rodrigues D. Arch Dis Child Educ Pract Ed 2014;99:208-212.

\title{
Fifteen-minute consultation: incidental findings on brain and spine imaging
}

\author{
Chirag Patel, Desiderio Rodrigues
}

\begin{abstract}
Incidental findings on imaging of the brain and spine account for a large number of referrals to a paediatric neurosurgical practice. They can be cause of undue concern to the parents and can result in unnecessary investigations and interventions. This article is a review of the common pathological entities identified as incidental findings in the author's experience. The list is not exhaustive and reflects mainly the common conditions referred. Very few of these incidental findings would need surgical intervention.
\end{abstract}

\section{INTRODUCTION}

Incidental findings on imaging studies in children is a common referral to a paediatric neurosurgical practice. This can be a source of concern for the parents, leading occasionally to poor advice about management of the condition and lifestyle choices, that is, sports, career and rarely unnecessary surgery.

The common unexpected findings on imaging are

- arachnoid cysts

- pineal cysts

- Chiari malformation/syringomyelia

- lipomas

vascular anomalies.

\section{ARACHNOID CYSTS}

An arachnoid cyst is a congenital lesion that develops due to abnormal duplication of arachnoid membrane adjacent to the brain and is filled with cerebrospinal fluid (CSF).

On imaging the prevalence is $2.6 \%{ }^{1}$ (all sizes) in ages 18 years and under, with a slight predominance in males. With current excellent imaging technology, arachnoid cysts may be reported in 10\% of MRI scans.

Arachnoid cysts can form wherever there is arachnoid membrane. The most common location is in the middle fossa.
They also occur in the posterior fossa, pineal region, sellar, convexity (cortical surface) and ventricular region.

Arachnoid cysts can be asymptomatic; however, it can present with subdural hygromas, haematoma or hydrocephalus.

Rarely, they can present with macrocephaly, epilepsy, headaches, cognitive symptoms or focal neurological deficits (figure 1).

\section{Management}

Arachnoid cysts are usually asymptomatic, and it is wise to adopt a conservative approach.

Rarely, arachnoid cysts can cause symptoms due to raised intracranial pressure or due to mass effect on the underlying brain. Head trauma can cause cyst rupture leading to subdural hygromas or haematomas requiring surgical intervention. This is more common in arachnoid cysts located on the cortical surface. Likewise, arachnoid cysts causing macrocephaly in infancy and obstructive hydrocephalus (pineal, posterior fossa cysts) may need addressing. Surgical options include arachnoid cyst fenestration (open microscopic or endoscopic) or shunt drainage. Surgery for arachnoid cysts causing epilepsy or behavioural/psychiatric disorders should be strongly supported by functional imaging.

\section{Follow-up of asymptomatic arachnoid cysts} Clinical and radiological surveillance would be appropriate for large arachnoid, cysts causing subacute mass effect or cysts located on cortical surface. Smaller arachnoid cysts can be left alone after reassuring the parents and child.

\section{Dilemma: should the child play contact sports?}

Sudural hygromas and intracystic haematomas with subdural extension have been 


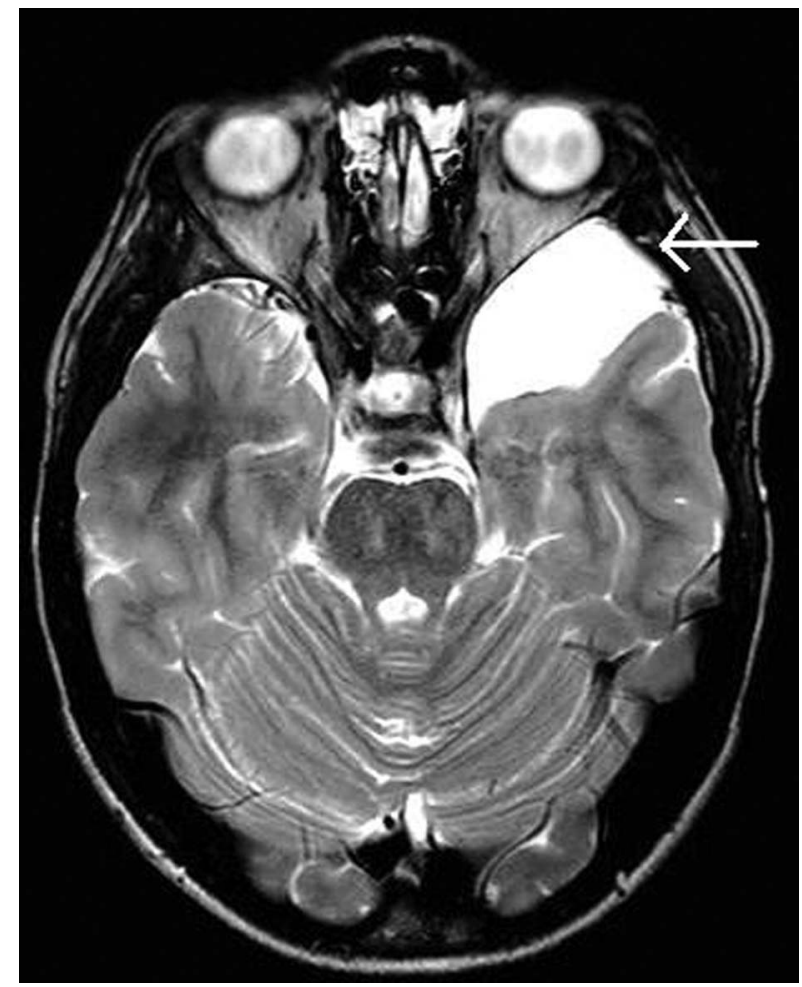

Figure 1 T2-weighted axial MRI scan brain showing an incidental left temporal fossa arachnoid cyst.

described in young patients even in the context of minor trauma. ${ }^{23}$ Therefore, there is a rationale for discouraging children with arachnoid cysts from participating in contact sports. The Amateur Boxing Association of England would not allow an individual to continue boxing after such a diagnosis. ${ }^{4}$

\section{PINEAL CYSTS}

A pineal cyst is a non-neoplastic cyst in the pineal gland, usually small, less than $2 \mathrm{~cm}$ with a thin wall, which may enhance with contrast administration.

Their prevalence on imaging studies is $0.6 \% .^{5}$

The cysts are commonly located within the substance of the pineal gland unlike arachnoid cysts that are located outside. The contents of the cyst do not have the same imaging characteristics as CSF.

The majority are incidental findings on imaging. Rarely, large expansile pineal cysts can present with headaches, hydrocephalus or midbrain dysfunction (figure 2).

\section{Management}

Majority are managed conservatively; however, neurosurgical consultation is appropriate in most cases especially if the pineal cysts are large (more than $2 \mathrm{~cm}$ ), thick-walled, multiseptate, enhancing with contrast or abutting the aqueduct.

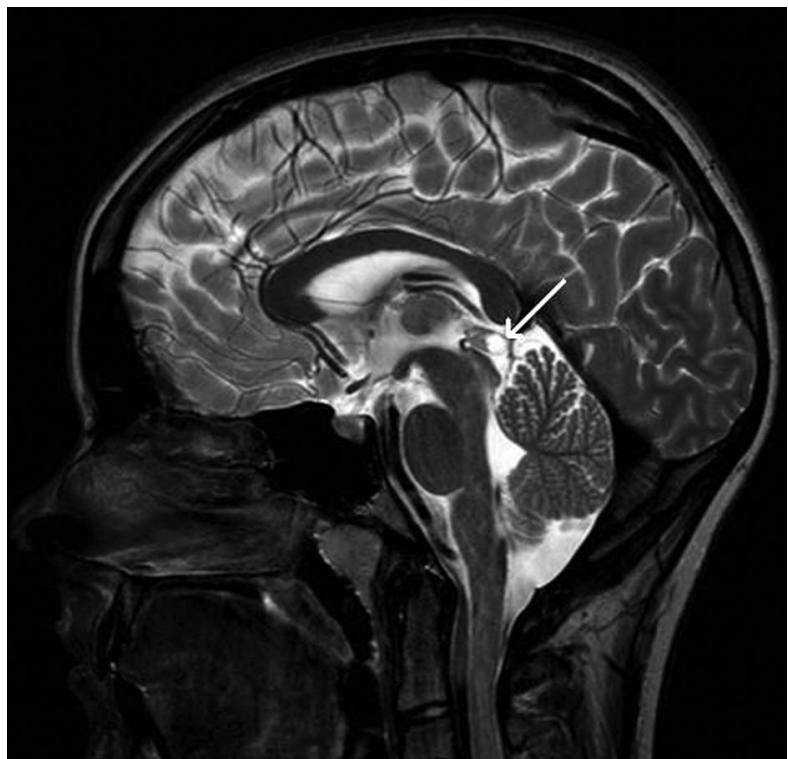

Figure 2 Sagittal T2-weighted MRI brain showing pineal cyst; note the intraparenchymal location and thin wall.

\section{Follow-up}

Pineal cysts may remain quiescent or involute or slowly enlarge over time. For this reason, clinical follow-up is needed, although sequential imaging is rarely indicated. ${ }^{67}$

\section{CHIARI MALFORMATIONS}

Chiari 1 malformations are herniation of the cerebellar tonsils $5 \mathrm{~mm}$ or more below the level of the foramen magnum (figure 3: dotted line) without additional or associated brain and posterior fossa anatomic abnormalities.

All patients who have a Chiari 1 malformation should have, at some point, full spine imaging to look for a frequent and important associated abnormality-a syringomyelia, which will require closer monitoring. ${ }^{8}$

The prevalence of Chiari 1 malformation on current MRI studies is $3.6 \%$, whereas the prevalence of Chiari 1 malformation with associated syrinx is $1.2 \%$ in girls and $0.5 \%$ in boys (figure 3 ). ${ }^{9}$

Chiari malformations can be asymptomatic, seen on imaging for unrelated symptoms. Classically, patients with Chiari 1 malformation can present with a reproducible tussive occipital head pain, which lasts few seconds to minutes.

The symptoms of Chiari syndrome can be subdivided into primary (cardinal) symptoms arising from the crowding at the foramen magnum due to an inadequate posterior fossa or spinal cord syrinx and secondary symptoms ascribed to the brain stem of the craniocervical junction area. 


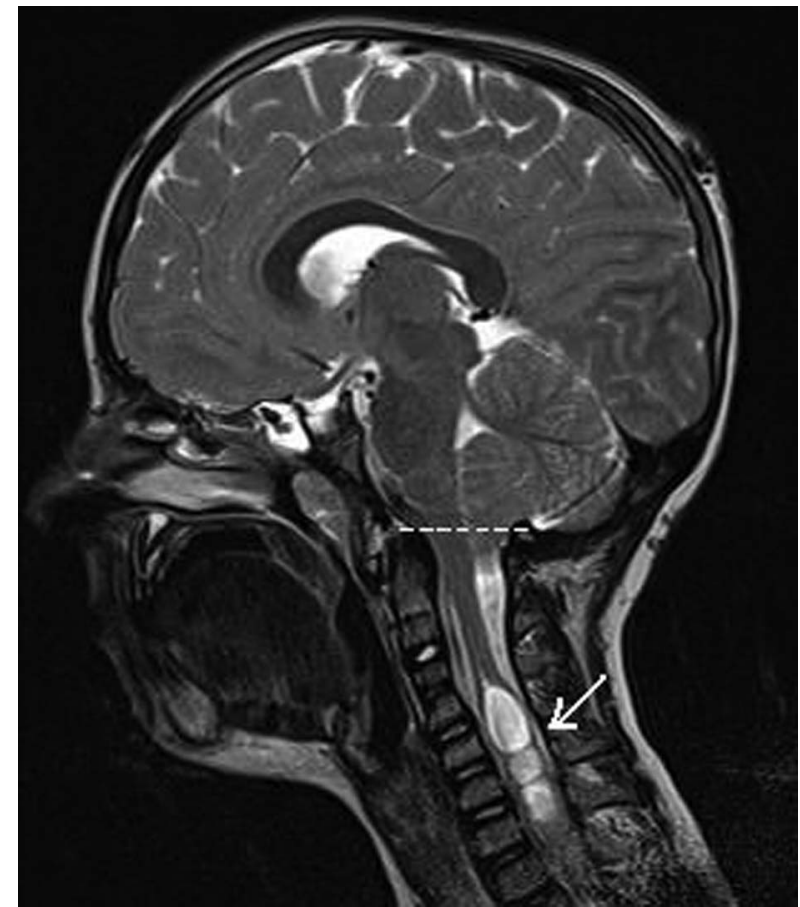

Figure 3 Sagittal T2-weighted MRI showing Chiari 1 malformation with a syrinx (white arrow) in the cervical cord. The dotted line shows level of the foramen magnum with tonsillar descent below it.
Primary symptoms
- Tussive headache
- Visual changes
- Syncope
- Muscle weakness
- Sensory deficits
- Dysphagia, dysarthia
- Ataxia

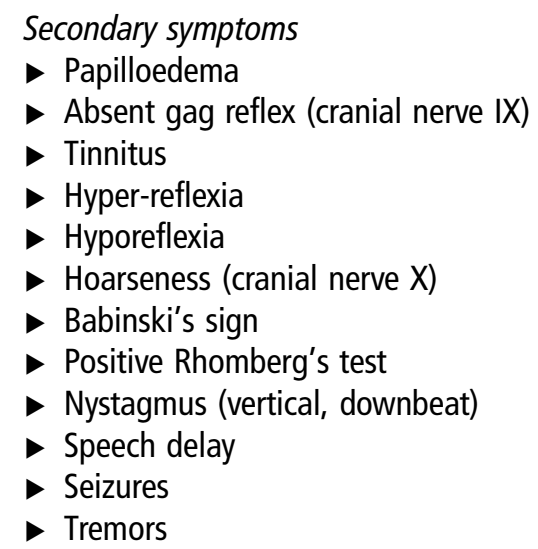

\section{Management}

Asymptomatic patients should be followed expectantly without further imaging as they rarely progress to significant symptomatology. ${ }^{10}$ Annual clinical surveillance is recommended with repeat imaging if there is any historical or neurological deterioration. In patients without syrinx, repeat MRI imaging is not recommended unless symptoms develop. ${ }^{8}$ There is no restriction of activities for these patients and patients are advised to report back if there is new onset of valsalva headaches or sensorimotor changes in limbs (pins and needles, loss of temperature sensation, weakness).

Children with Chiari 1 malformations with valsalvainduced headaches or neurological deficits including signs of spinal cord dysfunction due to syrinx should be evaluated by a neurologist or neurosurgeon experienced in the syndrome and its management. Postvalsalva headaches can be managed medically as first-line treatment.

There are various surgical options to enlarge the posterior fossa and promote CSF flow at the craniovertebral junction. Resolutions of symptoms of Chiari 1 malformations with a variety of operations range from $60 \%$ to $100 \% .^{10}$

Primary symptoms are likely to improve after surgical decompression, whereas secondary symptoms may improve if related to the malformation or may persist if not.

\section{LIPOMAS}

Lipomas are developmental aberrations that tend to appear in midline locations in the brain and spinal cord.

Common sites in the brain are in the corpus callosum, chiasm/hypothalamic region and pineal region. They are physiologically normal tissues in abnormal locations with growth potential similar to mature adipose tissue (figure 4$).^{11}$

Some may present with epilepsy, which is usually due to adjacent cortical dysplasia rather than the lipoma.

Surgical indications for intracranial lipomas are extremely limited. ${ }^{12}$

Lipomas in the filum terminale of the spinal cord are far more common. They cause problems because they interfere with the normal elastic quality of the filum terminale, hence restricting normal movements of the spinal cord within the spinal canal, a state called spinal cord tethering. It is considered a milder form of spinal bifida and may be associated with incomplete fusion of the posterior elements of the neural arch and caudal displacement of the conus medullaris below L2-3 level (figure 5).

Tethering of the spinal cord tends to affect the most caudal segment of the spinal cord, which can present as

- bladder and bowel voiding dysfunction;

- weakness and sensory changes in the distal lower limbs with gait disturbances;

- rarely scoliosis due to weakness of paraspinal muscles.

These children would require referral to a paediatric neurosurgeon for consideration of surgical detethering of the cord, which carries very low risks. Close observation is prudent for asymptomatic patients, especially during the growth years, to identify any neurological deterioration prompting surgical intervention. ${ }^{13}$ 


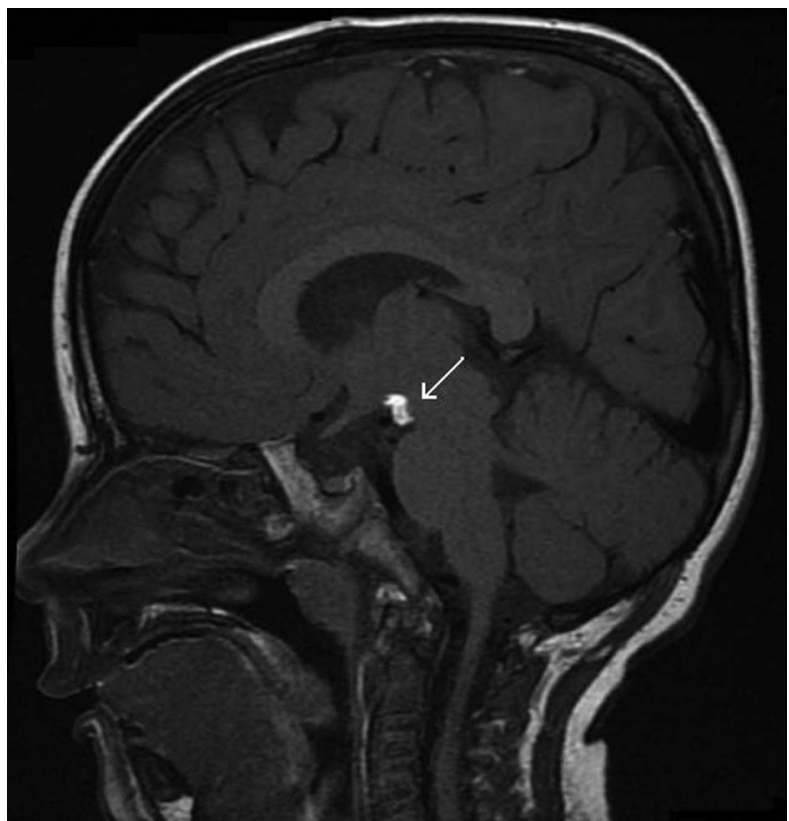

Figure 4 Sagittal T1 MRI brain showing hyper-intense signal anterior to the pons suggestive of lipoma.

Uncertainty arises when lipomas of filum terminale are picked up in MRI of children with non-specific symptoms like back pain and constipation. The

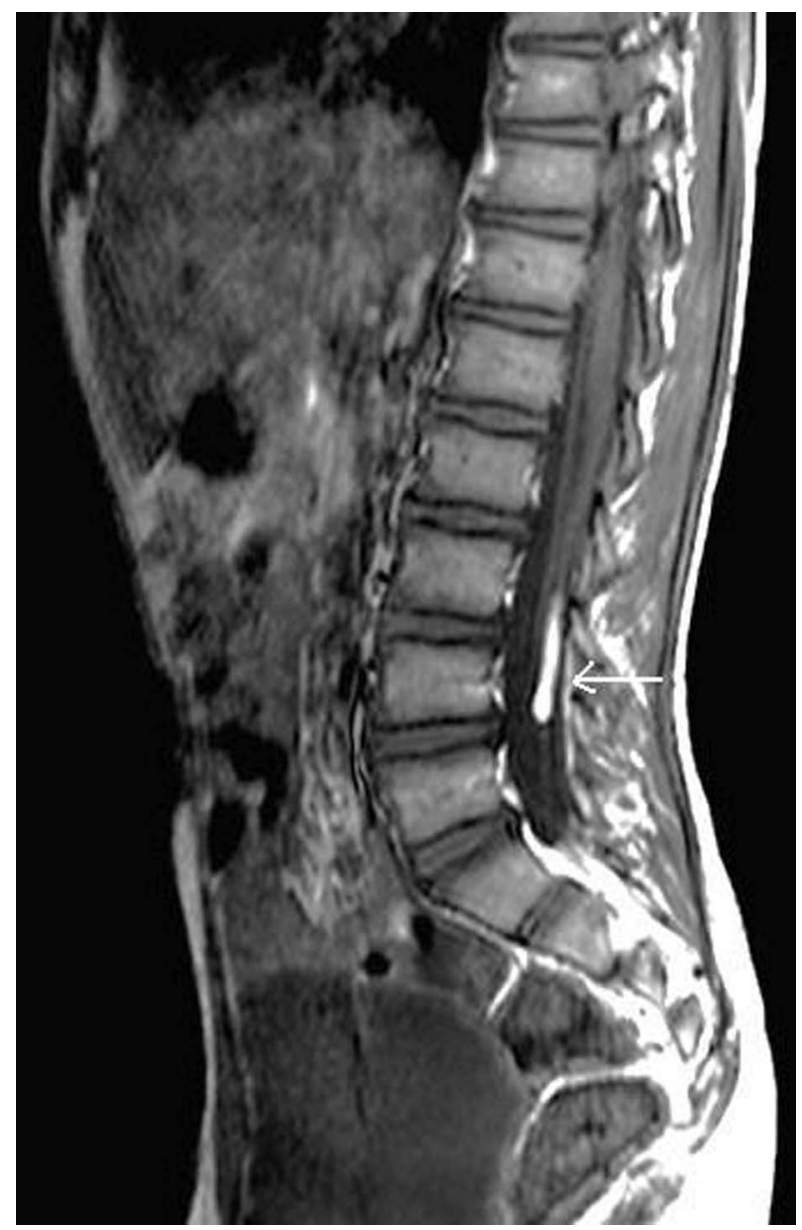

Figure 5 T1-weighted sagittal MRI of lumbar spine demonstrating a filum terminale lipoma (white arrow). problem is compounded by the paucity of literature bearing on the natural history of incidental filum terminale lipomas. These children would require consultation with a paediatric neurosurgeon and urologist along with urodynamics and neurophysiological testing to confirm the neurological nature of the nonspecific symptoms. Surgical intervention would be indicated in cases with progressive deterioration of symptoms and investigative finding. ${ }^{12} 13$

\section{DEVELOPMENTAL VENOUS ANOMALIES}

Developmental venous anomalies (DVA) are developmental aberrations of the larger cortical veins. The most common is the caput medusae consisting of multiple small subcortical veins (the snakes) draining into a large venous channel (Medusa's head).

DVA are not the cause of intracerebral haemorrhage; however, it may be associated with other vascular lesions like cavernomas, capillary telangiectasias and arteriovenous malformations. ${ }^{14}$

Modern MRI scanners are sufficiently sensitive in demonstrating isolated DVA, and no further imaging is required. The family can be reassured and surveillance is not indicated (figure 6).

The aim of this article is to prevent what is called a cascade effect, which can start with a general practitioner requesting an investigation in a child that picks up an incidental finding that is interpreted as abnormal. This is then referred to the paediatrician as the root cause of the child's symptoms. The paediatrician feels out of depth to address parents' concern and refers them to the neurosurgeon who, by the time he/she gets

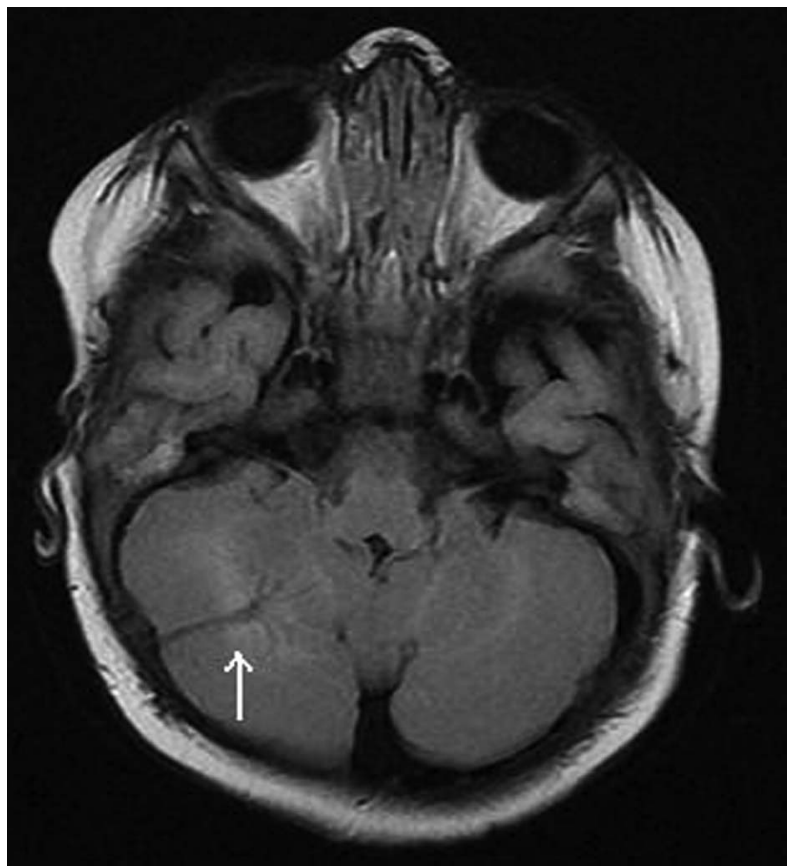

Figure 6 MRI brain axial fluid attenuated inversion recovery showing a developmental venous anomaly in the right cerebellar hemisphere with typical caput medusae pattern. 
Table 1 Management of incidental findings on MRI brain scans*

\begin{tabular}{|c|c|c|c|}
\hline Condition & Needs regular clinical review & Needs regular imaging & Needs referral to neurosurgeon \\
\hline $\begin{array}{l}\text { Chiari } 1 \\
\text { malformation } \\
\text { without syrinx }\end{array}$ & $\begin{array}{l}\text { Yes_annual follow for } 2 \text { years after } \\
\text { diagnosis and thereafter if any } \\
\text { Chiari-related symptoms }\end{array}$ & No-only if symptomatic & Yes \\
\hline $\begin{array}{l}\text { Chiari } 1 \\
\text { malformation with } \\
\text { syrinx }\end{array}$ & Yes-annual follow-up & $\begin{array}{l}\text { Repeat imaging at } 6 \text { months, } \\
1 \text { year followed by imaging on } \\
\text { clinical grounds }\end{array}$ & Yes \\
\hline Arachnoid cysts & $\begin{array}{l}\text { Yes-annual follow-up until schooling at } \\
5 \text { years and thereafter if any symptoms of } \\
\text { raised intracranial pressure }\end{array}$ & $\begin{array}{l}\text { Repeat imaging at } 1 \text { year, then } \\
\text { repeat if symptomatic }\end{array}$ & Yes \\
\hline Pineal cysts & $\begin{array}{l}\text { Yes-annual follow-up until school age } \\
\text { ( } 4-5 \text { years of age) }\end{array}$ & $\begin{array}{l}\text { Repeat imaging at } 6 \text { months, } \\
1 \text { year followed by imaging on } \\
\text { clinical grounds }\end{array}$ & Yes \\
\hline Intracranial lipomas & No & No & No \\
\hline $\begin{array}{l}\text { Filum terminale } \\
\text { lipomas }\end{array}$ & Yes & No-only if symptomatic & Yes \\
\hline $\begin{array}{l}\text { Dural venous } \\
\text { anomalies }\end{array}$ & No & No & $\begin{array}{l}\text { Yes_single consultation to rule out any } \\
\text { associated vascular anomalies, ie, aneurysm, } \\
\text { cavernoma, arteriovenous malformation }\end{array}$ \\
\hline
\end{tabular}

*Each case may have to be tailored to the patient's clinical situation, social and cultural factors.

to see the child, is confronted by anxious parents worried that their child has a dreadful condition.

However, due to the varied presentations of some of the incidental findings they would require referral to the neurosurgeon with further clinical or radiological follow-up. We hope that the summary table below will be helpful in making this decision.

\section{Competing interests None.}

Provenance and peer review Commissioned; externally peer reviewed.

\section{REFERENCES}

1 Wajd N, Al-Holou MD, Andrew Y, et al. Prevalence and natural history of arachnoid cysts in children: clinical article.

J Neurosurg Pediatr 2010;5:578-85.

2 Ildan F, Cetinalp E, Bagdatoglu H, et al. Arachnoid cyst with traumatic intracystic hemorrhage unassociated with subdural hematoma. Neurosurg Rev 1994;17:229-32.

3 Page A, Paxton RM, Mohan D. A reappraisal of the relationship between arachnoid cysts of the middle fossa and chronic subdural haematoma. J Neurol Neurosurg Psychiatry 1987;50:1001-7.

4 The Medical Commission of the Amateur Boxing Association of England Limited. Medical Aspects of Amateur Boxing. 4th edn. London, UK: Amateur Boxing Association of England Limited, 2002.
5 Sener RN. The pineal gland: a comparative MR imaging study in children and adults with respect to normal anatomical variations and pineal cysts. Pediatr Radiol 1995;25:245-8.

6 Barboriak DP, Lee L, Provenzale JM. Serial MR imaging of pineal cysts: implications for natural history and follow-up. AJR Am J Roentgenol 2001;176:737-43.

7 Al-Holou WN, Maher CO, Muraszko KM, et al. The natural history of pineal cysts in children and young adults. J Neurosurg Pediatr 2010;5:162-6.

8 Stevens JM, Serva WA, Kendall BE, et al. Chiari malformation in adults: relation of morphological aspects to clinical features and operative outcome. J Neurol Neurosurg Psychiatry 1993;56:1072-7.

9 Strahle J, Muraszko KM, Kapurch J, et al. Chiari malformation Type I and syrinx in children undergoing magnetic resonance imaging. J Neurosurg Pediatr 2011;8:205-13.

10 Yassari R, Frim D. Evaluation and management of the Chiari malformation type 1 for the primary care paediatrician. Pediatr Clin N Am 2004;51:477-90.

11 Truwit CL, Barkovich AJ. Pathogenesis of intracranial lipoma: an MR study in 42 patients. AJR Am J Roentgenol 1990;155:855-64.

12 Piatt JH. Unexpected findings on brain and spine imaging in children. Pediatr Clin N Am 2004;51:507-27.

13 Finn MA, Walker MA. Spinal lipomas: clinical spectrum, embryology and treatment. Neurosurg Focus 2007;23:E10.

14 Rigamonti D, Spetzler RF, Medina M, et al. Cerebral venous malformations. J Neurosurg 1990;73:560-4. 